\title{
Effect of quantity and quality of environmental stress on multilocus heterozygosity-growth relationships in Eisenia fetida (Annelida: Oligochaeta)
}

\author{
MICHELE C. AUDO \& WALTER J. DIEHL* \\ Department of Biological Sciences, PO Drawer GY, Mississippi State University, Starkville, MS 39762, U.S.A.
}

\begin{abstract}
The effects of environmental quantity (moderate soil moisture vs. low soil moisture) and quality (low soil moisture vs. low temperature) on multilocus heterozygosity (MLH)-growth relationships were tested in the earthworm Eisenia fetida. The control treatment was high soil moisture and high temperature. Fresh weight was measured weekly for 4 weeks; MLH was computed for eight polymorphic loci. Moderate moisture limited growth (change in fresh weight) to 50 per cent of control growth; both low moisture and low temperature limited growth to 25 per cent of control growth. MLH was not correlated with growth at any time in the control treatment. MLH was strongly correlated with growth $(P<0.01)$ in three out of four weekly intervals in the moderate moisture treatment; MLH was weakly correlated with growth $(P<0.05)$ in two out of four weekly intervals in the low moisture treatment. MLH was not correlated with growth at any time in the low temperature treatment. Moderate soil moisture produced significantly stronger MLH-growth relationships than high moisture or low temperature. Even though low soil moisture and low temperature depressed growth to the same extent, the former produced MLH-growth relationships whereas the latter did not. Thus both environmental quantity and quality affected the existence and recurrence of MLH-growth relationships.
\end{abstract}

Keywords: Eisenia fetida, environmental stress, growth, heterozygosity.

\section{Introduction}

Multilocus heterozygosity for allozyme loci (MLH) has been correlated with growth and fitness characteristics in numerous species (reviewed by Mitton \& Grant, 1984; Zouros \& Foltz, 1987). Environmental stress is thought to promote these relationships (Koehn et al., 1988 ), but there is little understanding about the effects of quantity and quality of stress on them. In this paper, quantity of environmental stress refers to different levels of a single variable whose effects differ in magnitude and are caused by a common set of metabolic mechanisms. Quality of environmental stress refers to comparable levels of different variables whose effects are similar in magnitude but are caused by different metabolic mechanisms.

Studies examining the effects of stress on MLH-fitness relationships fall into three categories. In some studies (e.g. Samollow \& Soulé, 1983; Diehl \& *Correspondence.
Koehm, 1985), the case that a stressful environment caused MLH-fitness relationships has been made $a$ posteriori. In other studies (e.g. Rodhouse \& Gaffney, 1984; Diehl et al., 1986), a single stressful treatment has been applied a priori to a set of experimental organisms to amplify MLH-fitness relationships (but see Houle, 1989). Finally, MLH-fitness relationships have been compared in organisms subjected to stressful vs. nonstressful conditions of various types. These latter studies have included comparisons of stressful vs. nonstressful field conditions (Green et al., 1983; Pecon Slattery et al., 1991), comparisons of stressful field vs. nonstressful laboratory conditions (Koehn et al., 1988 ), and comparisons of stressful vs. nonstressful laboratory conditions (Koehn \& Shumway, 1982; Diehl, 1988; Gentili \& Beaumont, 1988; Scott \& Koehn, 1990). Despite great differences in the types of environmental stress studied, MLH was usually correlated with fitness in stressed organisms but not in nonstressed organisms. 
Dogma holds that MLH-fitness relationships get stronger and easier to detect with increasing environmental stress, even though virtually all comparisons (where more than one treatment was involved) have used only one stressful and one nonstressful condition. An exception is the study of Scott \& Koehn (1990) who showed that in the coot clam Mulinia lateralis, a MLH-growth relationship occurred under temperature stress or salinity stress but not under both temperature and salinity stress combined. They concluded that the combined effects of fluctuating salinity and high temperature somehow negated the advantage of heterozygosity perhaps by producing a less stressful environment than either factor alone. This conclusion derives from the fact that temperature stress places different demands on the metabolism of an organism than does salinity stress (Hochachka \& Somero, 1984). An alternative explanation is that the strength of MLH-fitness relationships does not increase monotonically with stress and that the quality of environmental stress is not important. The use of two or more environmental factors to produce the most stressful condition does not allow these possibilities to be distinguished.

We have attempted to distinguish the effects of environmental quantity from the effects of environmental quality on MLH-growth relationships in the earthworm Eisenia fetida. Specifically, we tested the hypotheses that: (i) MLH-growth relationships would be stronger and more frequent as the severity of soil moisture stress increased; and (ii) the existence of MLH-growth relationships would depend on the quality of environmental stress. We compared effects of moderate and low moisture stress and low temperature stress (designed to be as stressful as the low moisture stress) on MLH-growth relationships during several weeks early in the ontogeny of $E$. fetida.

\section{Materials and methods}

Eisenia fetida were collected from a stock population of earthworms kept in the greenhouse of the Department of Biological Sciences at Mississippi State University (Starkville, MS, U.S.A.). This population has been maintained since 1987 and contained several thousand adult earthworms at the time of this experiment. The origin of this population has been described by Diehl (1988).

Juvenile earthworms (about 2 weeks old) were assigned haphazardly to one of four treatments differing in soil moisture and temperature $(n=100$ earthworms per treatment; mean initial weight $\approx 0.01 \mathrm{~g}$ per treatment). Earthworms were raised individually in 75 $\mathrm{mL}$ plastic cups containing neutral dry peat moss
(NDPM: 95 per cent dry peat moss; 5 per cent $\mathrm{CaCO}_{3}$ ). Treatment 1 (control) consisted of high soil moisture $(4$ $\mathrm{mL} \mathrm{H}_{2} \mathrm{O} / \mathrm{g}$ NDPM) and high temperature $\left(25^{\circ} \mathrm{C}\right)$. Treatment 2 consisted of moderate soil moisture $(3 \mathrm{~mL}$ $\left.\mathrm{H}_{2} \mathrm{O} / \mathrm{g} \mathrm{NDPM}\right)$ and high temperature $\left(25^{\circ} \mathrm{C}\right)$. Treatment 3 consisted of low soil moisture $\left(2 \mathrm{~mL} \mathrm{H}_{2} \mathrm{O} / \mathrm{g}\right.$ NDPM) and high temperature $\left(25^{\circ} \mathrm{C}\right)$. Treatment 4 consisted of high soil moisture ( $\left.4 \mathrm{~mL} \mathrm{H}_{2} \mathrm{O} / \mathrm{g} \mathrm{NDPM}\right)$ and low temperature $\left(15^{\circ} \mathrm{C}\right)$. These treatments differed in quantity and quality of environmental stress defined by the extent to which growth was depressed relative to the control. Pilot experiments established the control conditions (i.e. those conditions most favourable for growth) and established that the other treatments would limit growth according to the patterns shown in Fig. 1. Although reduced soil moisture levels depressed growth, these moisture levels were not sufficiently low to have an osmotic effect on the earthworms (Diehl \& Williams, 1992b).

At the beginning of the experiment and each week for 4 weeks, earthworms were rinsed of peat moss, blotted briefly on a paper towel, and weighed. Individual growth rates were computed as the change in fresh weight over either 1 week or 4 weeks depending on the analysis. Commercially prepared earthworm food (Carolina Biological Supply) supplemented with a soy-based baby formula was given ad libitum. Peat moss was changed and food was provided weekly. Drying was prevented by covering each container with aluminum foil. At the end of 4 weeks, all individuals were frozen at $-80^{\circ} \mathrm{C}$ until electrophoresis could be performed. Overall, mortality was about 10 per cent and occurred mostly during the first week in treatment

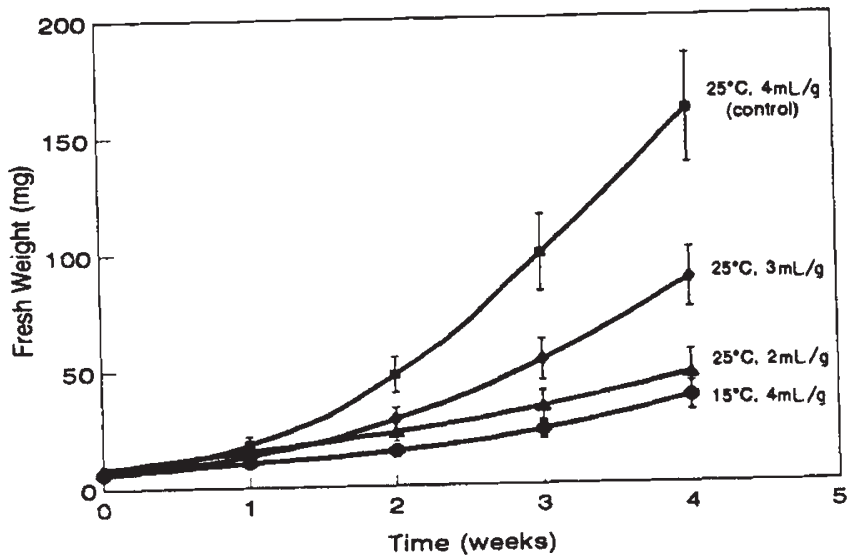

Fig. 1 Growth trajectories of Eisenia fetida in treatment 1 (control: $25^{\circ} \mathrm{C}, 4 \mathrm{~mL} \mathrm{H} \mathrm{H}_{2} \mathrm{O} / \mathrm{g}$ dry peat moss), treatment 2 $\left(25^{\circ} \mathrm{C}, 3 \mathrm{~mL} \mathrm{H}{ }_{2} \mathrm{O} / \mathrm{g}\right.$ dry peat moss $)$, treatment $3\left(25^{\circ} \mathrm{C}, 2 \mathrm{~mL}\right.$ $\mathrm{H}_{2} \mathrm{O} / \mathrm{g}$ dry peat moss $)$, and treatment $4\left(15^{\circ} \mathrm{C}, 4 \mathrm{~mL} \mathrm{H}_{2} \mathrm{O} / \mathrm{g}\right.$ dry peat moss) for the 4-week experimental period. Data are reported as means \pm SE. Symbols without error bars have standard errors that do not exceed the width of the symbol. 
3 (Table 1). Dead individuals were replaced with juvenile earthworms that were treated as above so that 100 earthworms in each treatment were available for electrophoresis. The initial weights and genetic compositions of the replacement earthworms were similar to those of the original sample. Therefore, replacing dead earthworms should not have affected the detection of MLH-growth relationships.

Each earthworm was scored for eight polymorphic loci by starch-gel electrophoresis. Earthworm homogenates were prepared by grinding a portion $(\approx 0.02 \mathrm{~g}$ ) of the tail posterior to segment 32 (the postclitellar region in adults) in $100 \mu \mathrm{L}$ of buffer containing $0.1 \mathrm{M}$ Tris/ $/ \mathrm{HCl} \mathrm{pH} \mathrm{7,20} \mathrm{per} \mathrm{cent} \mathrm{glycerol} \mathrm{and} 0.1$ per cent $\beta$-mercaptoethanol. For the small worms in treatments 3 and 4 , intact worms were homogenized in buffer to which phenylmethylsulfonyl fluoride $(0.1 \mathrm{~mm})$ had been added to retard the activity of proteolytic enzymes in the anterior portion of the worm. Homogenates were prepared as in Diehl (1988) as modified by Diehl \& Williams (1992a). Glycerol-3-phosphate dehydrogenase $(G p d 2, \quad$ EC 1.1.1.8), malate dehydrogenase ( $M d h$, EC 1.1.1.37), hexokinase ( $H k 2$, EC 2.7.1.1), alanyl aminopeptidase (Aap, EC 3.4.1.-), and mannose-6-phosphate isomerase (Mpi, EC 5.3.1.8) were resolved on the Tris-borate-EDTA, $\mathrm{pH}$ 8.7, buffer system of Pasteur et al. (1988). Hydroxybutyrate dehydrogenase ( $H b d$, EC 1.1.1.30), 6-phosphogluconate dehydrogenase (Pgd, EC 1.1.1.44), and phosphoglucomutase (Pgm, EC 2.7.5.1) were resolved on the Tris-maleate, $\mathrm{pH} 7.4$, buffer system of Selander \& Yang (1969). All loci except Aap and $H b d$ were stained according to Diehl \& Williams (1992a). Aap was stained according to Garton et al. (1984) and $H b d$ was stained according to Pasteur et al. (1988).

For each locus, earthworms were scored 0 if homozygous and 1 if heterozygous. MLH was the sum of these scores for the eight loci. Mean frequency of common alleles, multilocus heterozygosity $(\mathrm{MLH})$ and heterozygote deficiency $\left(D=\left(H_{\mathrm{o}}-H_{\mathrm{e}}\right) / H_{\mathrm{e}}\right.$; Selander, 1970) were computed for all earthworms in each treatment. Relationships between weekly growth (change in fresh weight) and MLH were determined by productmoment correlation (Sokal \& Rohlf, 1981) both with and without the sequential Bonferroni test (Rice, 1989) to control type I error within each treatment. Where correlations were significant, relationships were characterized using the Trend function of HARVARD GRAPHICS $3.0^{\circledR}$. The differences in strengths of the growth-MLH curves among treatments were tested by comparing correlation coefficients using $\chi^{2}$ (Zar, 1984). Correlation coefficients were separated using the $z$ transformation in a Student-Newman-Keuls (SNK)-type multiple range test according to $\mathrm{Zar}$ (1984). Other statistics are from Sokal \& Rohlf (1981) or Zar (1984). Data are reported as means \pm SE except where noted.

\section{Results}

Only earthworms with complete growth and genetic data were used in the analyses reported here. Reductions in sample sizes were most severe in treatments 3 and 4 (Table 1) in which earthworms were small and difficult to analyse electrophoretically for all loci,

Table 1 Population genetic characteristics of Eisenia fetida for each treatment and pooled among all individuals and treatments

\begin{tabular}{|c|c|c|c|c|c|}
\hline \multirow[b]{2}{*}{ Variable } & \multicolumn{4}{|c|}{ Treatment } & \multirow[b]{2}{*}{ Total } \\
\hline & $\begin{array}{c}1 \\
4 \mathrm{~mL} / \mathrm{g} ; 25^{\circ} \mathrm{C} \\
\text { (control) }\end{array}$ & $\stackrel{2}{3 \mathrm{~mL} / \mathrm{g} ; 25^{\circ} \mathrm{C}}$ & $\frac{3}{2 \mathrm{~mL} / \mathrm{g} ; 25^{\circ} \mathrm{C}}$ & $\frac{4}{4 \mathrm{~mL} / \mathrm{g} ; 15^{\circ} \mathrm{C}}$ & \\
\hline \multirow[t]{2}{*}{$f\left(a^{100}\right)$} & 0.696 & 0.632 & 0.685 & 0.717 & 0.678 \\
\hline & $(0.047)$ & $(0.057)$ & $(0.058)$ & $(0.048)$ & $(0.051)$ \\
\hline \multirow[t]{2}{*}{ MLH } & 2.802 & 3.435 & 2.686 & 3.574 & 3.087 \\
\hline & $(0.140)$ & $(0.147)$ & $(0.157)$ & $(0.210)$ & $(0.082)$ \\
\hline \multirow[t]{2}{*}{$D$} & -0.123 & 0.002 & -0.249 & 0.070 & -0.108 \\
\hline & $(0.055)$ & $(0.066)$ & $(0.116)$ & $(0.166)$ & $(0.083)$ \\
\hline Mortality (\%) & 0 & 4 & 27 & 6 & 10 \\
\hline$n$ & 86 & 85 & 70 & 47 & 288 \\
\hline
\end{tabular}

Values are means (SE).

Frequency of common alleles for all loci: $f\left(a^{100}\right)$; multilocus heterozygosity: MLH; heterozygote deficiency: $D$; sample size: $n$. 
especially $G p d 2$. Multilocus heterozygosity was significantly different among treatments (ANOvA: $\left.F_{3,284}=7.328 ; P<0.001\right)$. Common allele frequencies (arcsin-transformed data; $F_{3,28}=0.514 ; \quad N S$ ) and heterozygote deficiencies $\left(F_{3,28}=1.624 ; \mathrm{NS}\right)$ were not significantly different among treatments. The differences in MLH were most probably caused by sampling effects rather than by incomplete electrophoretic resolution. This is supported by the observation that the heterozygosities of several loci which were each resolved for at least 95 per cent of all individuals (e.g. $P g d, H k 2)$ were also different among treatments. It is possible that selection associated with differential mortality caused differences in MLH among treatments, but the lack of concordance between mortality and MLH (Table 1) does not support this hypothesis. Finally, sampling effects were also manifested as apparently strong heterozygote deficiencies in two treatments ( 1 and 3 ) that occurred because of random deviations from a slight (but not significant) heterozygote deficiency $(-0.108 \pm 0.083)$ in the whole population. In short, the data in Table 1 show the discrepancy in genetic characteristics that can occur among samples drawn from the same population.

Figure 1 shows the growth trajectories for each treatment during the 4-week experimental period. Sizes among the treatments began to diverge after the first week. By the end of the experiment, the average growth rate of earthworms in treatment 2 was 50 per cent of the growth rate of earthworms in the control treatment. The growth rates of earthworms in treatments 3 and 4 were similar to each other but were only 25 per cent of the growth rate of earthworms in the control treatment. No earthworm had attained sexual maturity, identified by the presence of a clitellum, by the end of the 4-week growth period.
Figures 2-5 show the MLH-growth curves for each weekly interval in the control, moderate moisture, low moisture and low temperature treatments, respectively. No significant MLH-growth rate relationships were observed for any weekly interval in the control or low temperature treatments (Figs 2, 5). However, significant relationships were observed in three of four intervals in the moderate moisture treatment (Fig. 3) and in two of four intervals in the low moisture treatment (Fig. 4). These latter two relationships were not significant if the sequential Bonferroni test was applied. In the moderate moisture treatment (Fig. 3), the amount of variation in growth that was explained by MLH increased progressively with time. No relationship was detected in the first week, but MLH explained 8 per cent of the variance in growth in the second week. MLH explained 15 per cent and 16 per cent of the variance in growth in the third and fourth weeks, respectively. Overall, MLH explained an average of 10 per cent of the variation in growth over 4 weeks in this treatment. In the low moisture treatment, no MLH-growth relationships were observed in the first and third weeks (Fig. 4). However, MLH explained 8 per cent and 6 per cent of the variation in growth in the second and fourth weeks, respectively. Overall, MLH explained an average of 3 per cent of the variation in growth in this treatment.

It is possible that the small sample sizes in treatments 3 and 4 affected our ability to detect MLH-growth relationships. Sample sizes of 278 and 31899 would be required in treatments 3 and 4, respectively, to match the power of the test overall in treatment 2 (0.985; Zar, 1984) assuming correlation coefficients were unchanged. However, if the sample of earthworms in treatment 3 had been similar to that in treatment $2(n=85)$, MLH-growth relationships
Fig. 2 Multilocus heterozygosity-growth relationships for Eisenia fetida for each week in treatment 1 (control: high moisture, $4 \mathrm{~mL} / \mathrm{g}$; high temperature, $\left.25^{\circ} \mathrm{C}\right)$. Significant MLH-growth correlations $(P<0.05)$ are indicated by solid lines (with Bonferroni test) or dashed lines (without Bonferroni test).

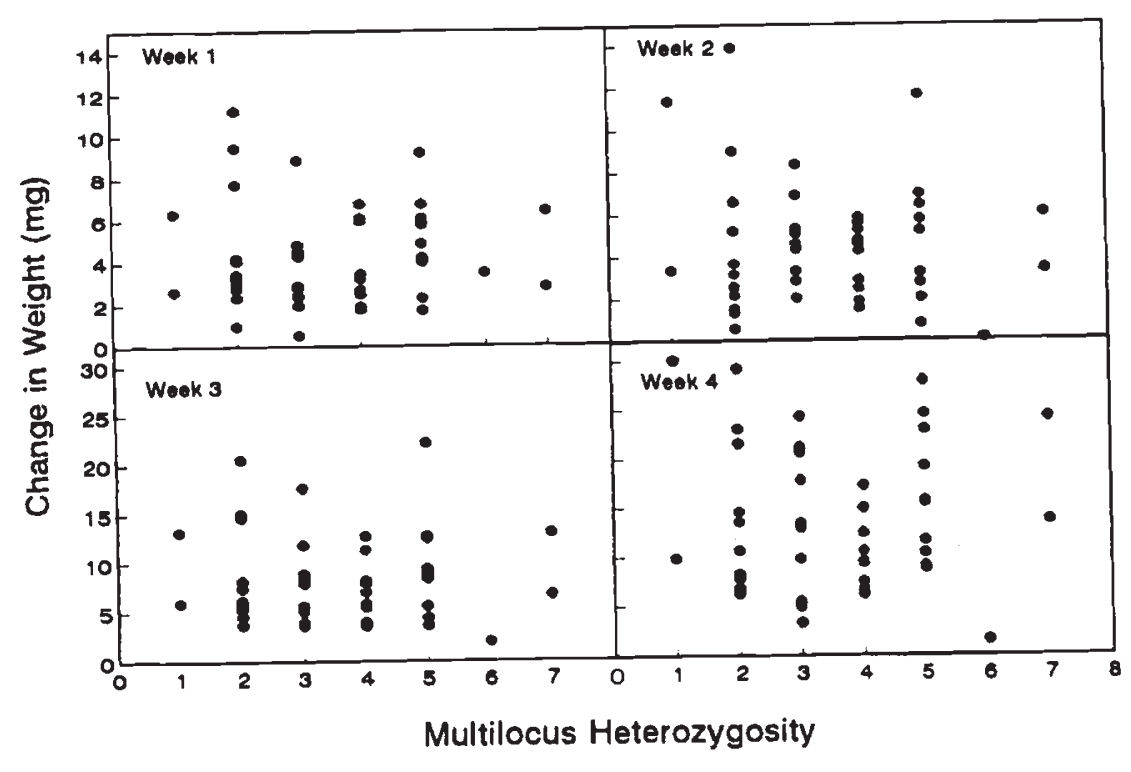



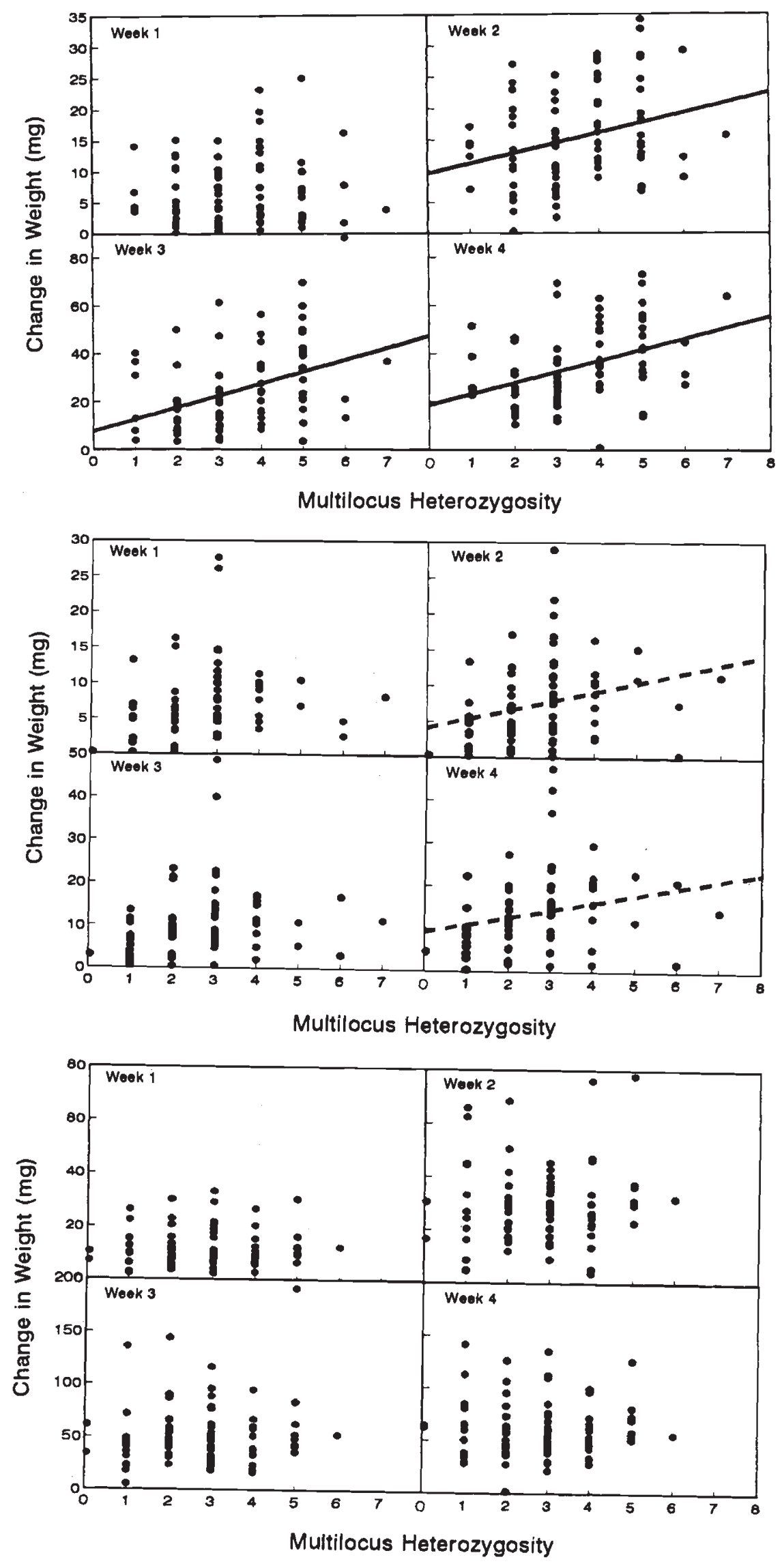

Fig. 3 Multilocus heterozygosity-growth relationships for Eisenia fetida for each week in treatment 2 (moderate moisture, $3 \mathrm{~mL} / \mathrm{g}$; high temperature, $\left.25^{\circ} \mathrm{C}\right)$. Significant MLH-growth correlations $(P<0.05)$ are indicated by solid lines (with Bonferroni test) or dashed lines (without Bonferroni test).

Fig. 4 Multilocus heterozygosity-growth relationships for Eisenia fetida for each week in treatment 3 (low moisture, $2 \mathrm{~mL} / \mathrm{g}$; high temperature, $\left.25^{\circ} \mathrm{C}\right)$. Significant MLH-growth correlations $(P<0.05)$ are indicated by solid lines (with Bonferroni test) or dashed lines (without Bonferroni test).
Fig. 5 Multilocus heterozygosity-growth relationships for Eisenia fetida for each week in treatment 4 (high moisture, $4 \mathrm{~mL} / \mathrm{g}$; low temperature, $15^{\circ} \mathrm{C}$ ). Significant MLH-growth correlations $(P<0.05)$ are indicated by solid lines (with Bonferroni test) or dashed lines (without Bonferroni test). 
would have been significant in three weekly intervals and one of these (week 2) would have retained its significance after the Bonferroni test was applied. Considering this, results are presented both with and without the sequential Bonferroni test, but results are discussed on the basis of significance without it.

Differences in strengths of the MLH-growth relationships were tested by comparing correlation coefficients of 4-week MLH-growth curves among treatments (Fig. 6). It was unnecessary to apply a Bonferroni test since the SNK-type multiple range test (Zar, 1984) is a simultaneous-inference test that already controls type I error. The correlation coefficient of the 4-week MLH-growth relationship in treatment 2 was significantly greater $(P<0.05)$ than those in treatments 1 and 4 . The correlation coefficient in treatment 3 was not significantly different $(P>0.05)$ from those in the other treatments.

\section{Discussion}

MLH-growth relationships have often been associated with genetic characteristics of the sample population, especially heterozygote deficiencies (see Zouros, 1987). The coincidence of MLH-growth relationships and heterozygote deficiencies in many species has been taken as evidence that a single mechanism must cause both phenomena (Gaffney et al., 1990), despite studies reporting no such associations (Garton et al., 1984; Diehl, 1988; Hu et al., 1993; Diehl \& Biesiot, 1994). In the present study, a positive MLH-growth relationship was associated with heterozygote deficiency in only one treatment (no. 3). However, this deficiency was

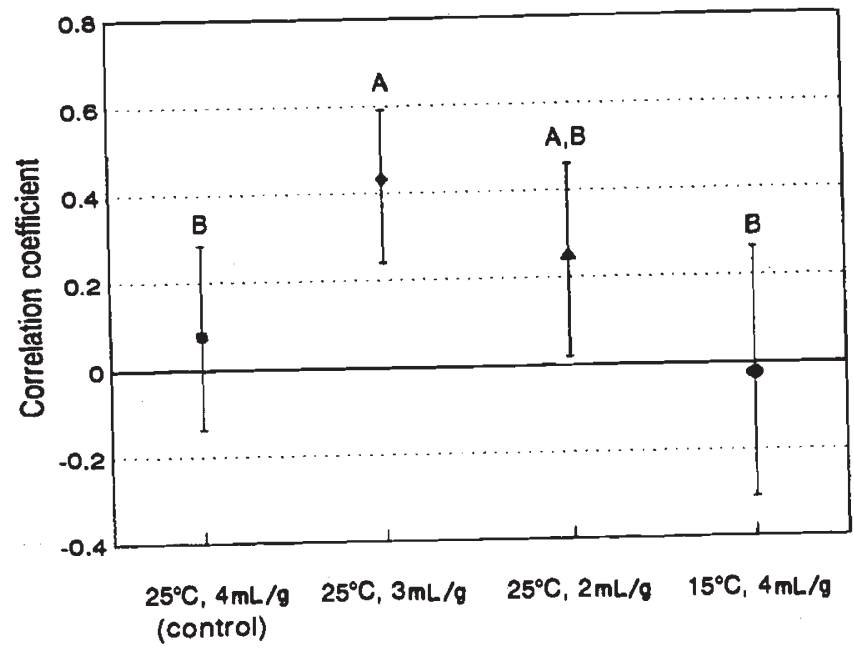

Fig. 6 Correlation coefficients of 4-week MLH-growth relationships with 95 per cent confidence intervals for each treatment. Correlation coefficients are significantly different $(P<0.05$, see text $)$ if letters above each interval are different. probably a sampling artefact because heterozygote deficiencies were not different among treatments and the overall deficiency was not different from zero. Also the treatment showing the strongest MLH-growth relationship (no. 2) had no heterozygote deficiency and the only other treatment with any heterozygote deficiency (no. 1) showed no MLH-growth relationship. In this experiment, there was little concordance between MLH-growth relationships and heterozygote deficiencies in any treatment. Although mechanisms explaining MLH-fitness relationships must be able to accommodate heterozygote deficiencies in populations where these phenomena co-occur, heterozygote deficiencies cannot be used to explain MLH-fitness relationships generally unless mechanisms for the latter are species-specific.

Several other random factors may affect one's ability to detect $\mathrm{MLH}$-growth relationships. These include sampling effects which have already been shown to affect genetic properties such as MLH among treatments. MLH-growth relationships might be affected if loci comprising MLH were sampled differently among treatments. This is unlikely as there was no more association between MLH-growth relationships and MLH than there was between the former and heterozygote deficiency. It is also possible that MLH-growth relationships may depend on the variation in growth available for analysis, especially if fewer individuals occur in a treatment where such variation is low. A simulation was run on the data from treatment 2 , week 4 , in which the 20 individuals showing the greatest growth (upper 24 per cent) and the 20 individuals showing the least growth (lower 24 per cent) were removed from the MLH-growth analysis. Variation in growth was reduced to levels less than that found in the same week in treatments 3 and 4 , and yet there was little effect on the MLH-growth relationship $(r=0.388$, d.f. $=43, P<0.01)$. Thus, it would seem unlikely that factors unrelated to the effects of the treatments themselves have caused the pattern of MLH-growth relationships observed.

In Eisenia fetida, loci contributed heterogeneously to the MLH-growth relationships (Diehl, 1988). Only loci which contributed positively or neutrally to the MLH-growth relationship in that study were used in the present study together with two loci $(H b d, A a p)$ that had not been resolved previously. When loci common to both studies were used to compute MLH, positive MLH-growth relationships occurred in both generations of earthworms that were raised under conditions that included a suboptimal soil moisture. Thus MLH-growth relationships have been shown twice in the same population sampled 7 years apart. This corresponds to about 40 generations between studies, assuming a 30 -day cocoon incubation period 
(Reinecke \& Venter, 1987) and a period of 4-6 weeks to sexual maturity after hatching (Hartenstein et al., 1979).

MLH-growth relationships occurred for 3 consecutive weeks early in the ontogeny of $E$. fetida raised in the moderate moisture treatment. The weekly increase in coefficients of determination for these relationships reflected the cumulative effect of MLH-growth relationships from previous intervals rather than a strengthening of MLH-growth relationships per se as ontogeny progressed. This pattern was not observed in the low soil moisture treatment where significant MLH-growth relationships occurred in two nonconsecutive intervals. Whether coefficients of determination would have increased with time as in the moderate moisture treatment is unknown. Regardless, E. fetida joins a small set of species (e.g. Mytilus edulis; Gaffney, 1990) in which MLH-fitness relationships have been shown repeatedly, both within and among generations.

Contrary to expectations, the treatment showing the strongest MLH-growth relationship was the moderate moisture treatment, not the low moisture treatment. Similarly, Scott \& Koehn (1990) showed that intermediate stresses of either temperature or salinity alone produced stronger MLH-growth relationships in Mulinia lateralis than the more severe combination of temperature and salinity stress. Temperature stress alone produced a growth rate nearly halfway between that reported for the control treatment and the combined-stress treatment and also produced the strongest MLH-growth relationship. Mitton (1993) was the first to suggest that moderate stress might be expected to produce stronger MLH-fitness relationships than severe stress, although he did not provide an explanation for this. The explanation of Scott \& Koehn (1990) concerning the negating effects of two or more adverse environmental conditions is not pertinent here because only one environmental variable was manipulated for this comparison. A more appropriate explanation derives from the energetic basis on which MLH-fitness relationships are thought to be founded (Koehn \& Bayne, 1989), especially as low soil moisture is known to have an adverse effect on the energy metabolism of $E$. fetida. Low soil moisture depresses respiration and heart beat rates presumably by limiting cutaneous diffusion of $\mathrm{O}_{2}$ (Diehl \& Williams, 1992b), and in compensation, accelerates glycolytic metabolism using glycogen as a fuel (Williams \& Diehl, 1992). MLH-fitness relationships must arise from a balance between energetic economy produced by genetic properties of the individual and energetic cost caused by adverse effects of the environment. When the environment is benign, individuals have more than enough energy to meet all their physiological needs and the slight benefits of heterozygosity are masked. When the environment is too stressful, the energy available for physiological processes is so limiting that the slight benefits of heterozygosity are inconsequential. However, when the environment is moderately stressful, the energetic benefits of heterozygosity are maximized relative to the demands on the organism and produce the strongest MLH-fitness relationships.

The effect of environmental quality on MLH-growth relationships is more difficult to determine because the experimental design was based on the prediction that the most stressful treatments would produce the strongest relationships. Low temperature produced no MLH-growth relationship and low moisture produced a weak relationship, despite each treatment depressing growth to the same extent. This difference is sufficient to admit the possibility of at least a marginal effect of environmental quality. Nevertheless, one cannot know from this experiment whether any deviation in temperature from 'optimum' would ever cause a MLH-growth relationship or whether a pattern similar to that observed for soil moisture would be observed if a range of temperatures was tested.

In summary, MLH-growth relationships occur repeatedly early in the ontogeny of Eisenia fetida and from generation to generation when earthworms are tested under appropriate environmental conditions. MLH-growth relationships depend on environmental quantity and perhaps on environmental quality. MLH-growth relationships did not occur in earthworms raised in optimal, low stress conditions. The strongest and most repeatable MLH-growth relationships occurred in earthworms raised in moderate soil moisture rather than in low soil moisture or low temperature.

\section{Acknowledgements}

We thank Ronn Altig for making useful comments on a draft of this paper. This research was supported by a Sigma Xi Grant-in-Aid of Research to M.C.A. and by NSF grant DEB-922 1094 to W.J.D.

\section{References}

DIEHL, w. J. 1988. Genetics of carbohydrate metabolism and growth in Eisenia foetida (Oligochaeta: Lumbricidae). Heredity, 61, 379-387.

DIEHL, W. J. AND BIESIOT, P. M. 1994. Relationships between multilocus heterozygosity and morphometric indices in a population of the deep-sea red crab Chaceon quinquedens (Smith). J. Exp. Mar. Biol. Ecol., 182, 237-250. 
DIEHL, W. J., GAFFNEY, P. M. AND KOEHN, R. K. 1986. Physiological and genetic aspects of growth in the mussel Mytilus edulis. I. Oxygen consumption, growth and weight loss. Physiol. Zool., 59, 201-211.

DIEHL, W. J. AND KOEHN, R. K. 1985. Multiple-locus heterozygosity, mortality, and growth in a cohort of Mytilus edulis. Mar. Biol., 88, 265-271.

DIEHL, w. J. AND WLLLIAMS, D. L. 1992a. Distributions of polymorphisms among pathways of carbohydrate metabolism in the earthworm Eisenia fetida (Oligochaeta). Comp. Biochem. Physiol., 101B, 83-90.

DIEHL, W. J. AND WILLIAMS, D. L. 1992b. Interactive effects of soil moisture and food on growth and aerobic metabolism in Eisenia fetida (Oligochaeta). Comp. Biochem. Physiol., 102A, 179-184.

GAFFNEY, P. M. 1990. Enzyme heterozygosity, growth rates, and viability in Mytilus edulis: another look. Evolution, 44, 204-210.

GAFFNEY, P. M., SCOTT, T. M., KOEHN, R. K. AND DIEHL, W. J. 1990. Interrelationships of heterozygosity, growth rate and heterozygote deficiencies in the coot clam, Mulinia lateralis. Genetics, 124, 687-699.

GARTON, D. W., KOEHN, R. K. AND SCOTT, T. M. 1984. Multiple-locus heterozygosity and the physiological energetics of growth in the coot clam, Mulinia lateralis, from a natural population. Genetics, 108, 445-455.

GENTILI, M. R. AND BEAUMONT, A. R. 1988. Environmental stress, heterozygosity, and growth rate in Mytilus edulis L. J. Exp. Mar. Biol. Ecol., 120, 145-153.

GREEN, R. H., SINGH, S. M., HICKS, B. AND McCUAIG, J. M. 1983. An arctic intertidal population of Macoma balthica (Mollusca, Pelecypoda): genotypic and phenotypic components of population structure. Can. J. Fish. Aquat. Sci., 40, 1360-1371.

HARTENSTEIN, R., NeUhaUSER, E. F. AND KAPLAN, D. L. 1979. Reproductive potential of the earthworm Eisenia foetida. Oecologia, 43, 329-340.

HOCHACHKA, P. W. AND SOMERO, G. N. 1984. Biochemical Adaptation. Princeton University Press, Princeton, NJ.

HOULE, D. 1989. Allozyme-associated heterosis in Drosophila melanogaster. Genetics, 123, 789-801.

HU, Y.-P., LUTZ, R. A. AND VRIJENHOEK, R. C. 1993. Overdominance in early life stages of an American oyster strain. $J$. Hered., 84, 254-258.

KOEHN, R. K. AND BAYNE, B. L. 1989. Towards a physiological and genetical understanding of the energetics of the stress response. In: Calow, P. and Berry, R. J. (eds) Evolution, Ecology and Environmental Stress, pp. 157-171. Academic Press, London.

KOEHN, R. K., DIEHL, W. J. AND SCOTT, T. M. 1988. The differential contribution by individual enzymes of glycolysis and protein catabolism to the relationship between hetero- zygosity and growth rate in the coot clam, Mulinia lateralis. Genetics, 118, 121-130.

KOEHN, R. K. AND SHUMWAY, S. E. 1982. A genetic/physiological explanation for differential growth rate among individuals of the oyster Crassostrea virginica (Gmelin). Mar. Biol. Lett., 3, 35-42.

MITTON, J. B. 1993. Enzyme heterozygosity, metabolism, and developmental stability. Genetica, 89, 47-65.

MITTON, J. B. AND GRANT, M. C. 1984. Associations among protein heterozygosity, growth rate, and developmental homeostasis. Ann. Rev. Ecol. Syst., 15, 479-499.

PASTEUR, N., PASTEUR, G., BONHOMME, R., CATALAN, J. AND BRITTONDAvidian, J. 1988. Practical Isozyme Genetics. John Wiley and Sons, New York.

PECON SLATTERY, J., VRIJENHOEK, R. C. AND LUTZ, R. A. 1991. Heterozygosity, growth, and survival of the hard clam, Mercenaria mercenaria, in seagrass vs sandflat habitats. Mar. Biol., 111, 335-342.

REINECKE, A. J. AND VENTER, J. M. 1987. Moisture preferences, growth and reproduction of the compost worm Eisenia fetida (Oligochaeta). Biol. Fert. Soils, 3, 135-141.

RICE, W. R. 1989. Analyzing tables of statistical tests. Evolution, 43, 223-225.

RODHOUSE, P. G. AND GAFFNEY, P. 1984. Effect of heterozygosity on metabolism during starvation in the American oyster Crassostrea virginica. Mar. Biol., 80, 179-187.

SAMOLLOW, P. B. AND SOULE, M. E. 1983. A case of stress related heterozygote superiority in nature. Evolution, 37, 646-649.

SCOTT, T. M. AND KOEHN, R. K. 1990. The effect of environmental stress on the relationship of heterozygosity to growth rate in the coot clam Mulinia lateralis (Say). J. Exp. Mar. Biol. Ecol., 135, 109-116.

SELANDER, R. K. 1970. Behavior and genetic variation in natural populations. Am. Zool., 10, 53-66.

SELANDER, R, K. AND YANG, S. Y. 1969. Protein polymorphism and genic heterozygosity in a wild population of the house mouse (Mus musculus). Genetics, 63, 653-667.

SOKAL, R. R. AND ROHLF, F. J. 1981. Biometry 2nd edn. W. H. Freeman and Co., San Francisco.

WILLIAMS, D. L. AND DIEHL, w. J. 1992. Interactive effects of soil moisture and food on glycolytic metabolism in Eisenia fetida (Oligochaeta). Comp. Biochem. Physiol., 102B, 911-917.

ZAR, J. H. 1984. Biostatistical Analysis. Prentice-Hall, Englewood Cliffs, NJ.

zouros, E. 1987. On the relation between heterozygosity and heterosis: an evaluation of the evidence from marine mollusks. Isozymes: Curr. Top. Biol. Med. Res., 15, 255-270.

zouros, E. AND FOLTZ, D. w. 1987. The use of allelic isozyme variation for the study of heterosis. Isozymes: Curr. Top. Biol. Med. Res., 13, 1-59. 